\title{
AVALIAÇÃO AGRONÔMICA DE CULTIVARES DE VIDEIRAS APIRENAS NA REGIÃO DE JAÍBA, MINAS GERAIS ${ }^{1}$
}

\author{
NELSON PIRES FELDBERG ${ }^{2}$, MÁRIO SÉRGIO CARVALHO DIAS ${ }^{3}$, MURILLO DEALBUQUERQUE REGINA $^{4}$
}

RESUMO - Atualmente, há interesse crescente no cultivo de cultivares de uvas apirenas no Brasil, devido ao aumento na demanda e ao alto valor recebido pelos seus frutos, além da possibilidade de produção em épocas de pouca oferta no mercado mundial. Este trabalho teve o objetivo de introduzir e avaliar o desempenho agronômico das cultivares Catalunha, Sultanina, Crimson Seedless e Superior Seedless enxertadas sobre 'IAC 572 Jales'. O experimento foi realizado na Fazenda Experimental da EPAMIG, em Mocambinho, distrito de Jaíba-MG, em delineamento inteiramente casualizado, com sete repetições. Foram analisados a fertilidade de gemas, o número e a massa de cachos, e o número e a massa de ramos. O ciclo, da poda à colheita dos cachos, foi de 97 dias para 'Superior Seedless', 104 dias para 'Sultanina', 106 dias para 'Catalunha' e 125 dias para 'Crimson Seedless'. As melhores produtividades foram obtidas nas safras com podas realizadas no primeiro semestre de cada ano, para todas as cultivares. 'Catalunha' apresentou os melhores resultados quanto ao número de cachos por planta e fertilidade de gemas, atingindo produtividade média de 19,0t/ha/ano. A cultivar Catalunha pode ser indicada para o cultivo em Jaíba-MG, sendo, entretanto, necessários novos estudos de manejo para o aumento da fertilidade de gemas de 'Crimson Seedless', 'Sultanina' e 'Superior Seedless'.

Termos para Indexação: vigor, fertilidade de gemas, produtividade, Vitis vinifera L., uvas apirenas.

\section{AGRONOMIC PERFORMANCE OF SEEDLESS VINES IN THE JAÍBA REGION, MINAS GERAIS}

ABSTRACT - There has been an increasing interest in the cultivation of seedless grapes cultivars in Brazil, due to the demand upgrade and the high revenues generated by their fruits, not to mention the fact that they can also be produced in time of low supply in the international market. This work had the objective to introduce and evaluate the agronomic performance of Catalunha, Sultanina, Crimson Seedless and Superior Seedless cultivars grafted in the 'IAC 572 Jales' rootstock. The experiment was carried out in the EPAMIG Experimental Farm in Mocambinho, district of Jaiba, MG, in a completely randomized experimental design with seven replications. Analyses were done on bud fertility, number and weight of clusters and cane number and weight. The cycle from pruning to harvest was 97 days for 'Superior Seedless', 104 days for 'Sultanina', 106 days for 'Catalunha' and 125 days for 'Crimson Seedless'. The best productivities were obtained in the harvests done in the first semester each year, for all cultivars. 'Catalunha' has shown the best results regarding the number of clusters per plant and bud fertility, with an average productivity of 19.0t/ha/year. 'Catalunha' can be recommended for cultivation in Jaíba, MG, and further studies are necessary to be able to increase bud fertility of 'Crimson Seedless', 'Sultanina' and 'Superior Seedless'.

Index Terms: vigor, bud fertility, productivity, Vitis vinifera L., seedless grapes.

\section{INTRODUÇÃO}

Em 2004, a uva de mesa representava apenas a sexta fruta em volume de exportação, entre outras nove frutas frescas que constavam da pauta de exportações brasileira (AGRIANUAL, 2006). Entretanto, quando se considerou o valor recebido por quilo de fruta exportada, a uva foi a primeira, com valores de US\$ 1,83 , muito superiores aos obtidos, por exemplo, pelo coco-dabaía (US\$ 0,53), limão e lima (US\$ 0,49) e maçã (US\$ 0,47). Segundo os dados de BRASIL (2006), em 2004, o Brasil exportou cerca de 29 mil toneladas de uvas frescas, principalmente para a Holanda, Reino Unido, Estados Unidos e Alemanha; e importou 6 mil toneladas, principalmente da Argentina e Chile. Embora o País ocupe lugar de pouca importância no mercado internacional de uvas de mesa, no período de 1996 a 2004, houve um aumento médio nas exportações de $31,6 \%$ ao ano e queda de $12,7 \%$ ao ano nas importações. Por outro lado, Protas (2004) afirmou que há evidências da preferência dos consumidores por uvas apirenas, o que representaria uma ameaça em termos de concorrência, já que grande parte da matriz produtiva dos parreirais brasileiros estava baseada em cultivares com sementes. Feitosa (2002) relatou que, em Petrolina-PE e Juazeiro-BA, principais regiões exportadoras de uvas do País, a cultivar Itália respondia por cerca de $63,2 \%$ do total da área plantada e era a principal cultivar exportada. Lagos (2005) observou que o sucesso do Chile como exportador de uvas, em parte, se deve ao cultivo de cultivares que atendem ao gosto dos importadores, principalmente ingleses e americanos, com preferência por cultivares apirenas. A produção de uvas apirenas no Brasil é recente e ainda faltam subsídios

'(Trabalho 192-07). Recebido em: 13-08-2007. Aceito para publicação em: 28-03-2008. Projeto financiado pelo CNPq.

${ }^{2}$ Bolsista CNPq - Embrapa Transferência de Tecnologia, Av. André Tosello, 209-Cidade Universitária, C.P. 6062, 13083-970, Campinas-SP npfeldberg@yahoo.com.br

${ }^{3}$ Epamig-Centro Tecnologico do Norte de Minas, Rod. MGT 122, Km 155, C.P. 12, 39525-000, Nova Porteirinha-MG. mariodias@epamig.br

${ }^{4}$ Núcleo Tecnológico EPAMIG Uva e Vinho, Av.Santa Cruz, 500 C.P.33, 37780-000, Caldas-MG. murillo@epamigcaldas.gov.br

Rev. Bras. Frutic., Jaboticabal - SP, v. 30, n. 3, p. 644-648, Setembro 2008 
tecnológicos capazes de torná-la mais eficaz. Neste sentido, o objetivo deste trabalho foi o de verificar o desempenho agronômico de quatro cultivares de uvas apirenas de grande aceitação no mercado mundial na região de Jaíba, norte de Minas Gerais.

\section{MATERIAL E MÉTODOS}

O experimento foi realizado na Fazenda Experimental de Mocambinho, da Empresa de Pesquisa Agropecuária de Minas Gerais (EPAMIG), localizada na região norte do Estado de Minas Gerais, entre os rios São Francisco e Verde Grande, a $15^{\circ} 00^{\prime}$ S. e $43^{\circ} 40^{\prime} \mathrm{O}$., e altitude de 449 metros acima do nível do mar. A temperatura média anual é de $24,2^{\circ} \mathrm{C}$, com média das mínimas de $14,8^{\circ} \mathrm{C}$ e média das máximas de $34,0^{\circ} \mathrm{C}$. A umidade relativa do ar varia entre $58 \%$ e $79 \%$. A insolação é de 2.892 horas/ano, e a precipitação média anual é de cerca de $900 \mathrm{~mm}$, concentrando-se nos meses de outubro a março, tendo raras precipitações no período seco (CODEVASF, 2004). O vinhedo experimental foi implantado em 2001 por meio da enxertia de campo no portaenxerto 'IAC 572 Jales'. O sistema de condução adotado foi o de pérgula, com espaçamento de 3 metros entre as plantas e 3 metros entre as linhas, e as plantas conduzidas, formando dois cordões principais do tipo "espinha de peixe". As plantas foram irrigadas por microaspersão. A poda foi realizada duas vezes ao ano, deixando-se em todas as safras ramos produtivos com 6 a 12 gemas e esporões com 2 a 3 gemas. Foram avaliadas as cinco primeiras safras a partir do primeiro semestre do ano de 2003, sendo duas com a colheita no final da primavera-início do verão, que corresponde ao período chuvoso, e três no final do outonoinício do inverno, que compreende o período de baixa pluviosidade. As podas foram realizadas em 17-03-2003, 26-082003, 19-02-2004, 05-08-2004 e 05-03-2005. As variáveis analisadas foram: massa total de cachos, número de cachos, número de ramos e massa total de ramos, em cada planta. Logo após a poda de cada ciclo, as folhas foram retiradas, e os ramos de cada planta foram pesados, com exceção da primeira poda, quando as plantas ainda estavam em fase de formação da estrutura produtiva e não apresentavam esporões e varas de produção definidos. A contagem dos ramos também se deu no início do ciclo. Os cachos foram contados e pesados no momento da colheita. Com tais variáveis, calculou-se a massa média dos cachos de cada planta. Para o cálculo da fertilidade de gemas, dividiu-se o número de cachos produzidos, pelo número total de ramos em cada planta. O delineamento experimental utilizado foi o inteiramente casualizado, sendo os tratamentos representados pelas cultivares, com sete repetições. Cada repetição foi composta por uma planta. As plantas avaliadas foram selecionadas e marcadas antes da primeira avaliação, buscando-se aquelas visualmente mais homogêneas quanto ao vigor e padrão de formação da estrutura produtiva. Os dados obtidos foram submetidos à análise de variância, utilizando-se o teste $\mathrm{F}$ e, para a comparação das médias, foi utilizado o teste de Tukey, a $1 \%$ e $5 \%$ de probabilidade. Para a comparação das produtividades, foi utilizado o teste de Scott Knott, a 5\% de probabilidade.

\section{RESULTADOS E DISCUSSÃO}

O ciclo das cultivares estudadas, da poda à colheita dos cachos, foi de 97 dias para 'Superior Seedless', 104 dias para 'Sultanina', 106 dias para 'Catalunha' e 125 dias para 'Crimson Seedless'.

Os dados referentes às massas de ramos obtidos no experimento encontram-se na Tabela 1. De maneira geral, a cultivar com a maior massa de ramos foi a 'Superior Seedless'. As cultivares Catalunha e Crimson Seedless apresentaram massas de ramos intermediárias, enquanto os ramos podados de Sultanina foram os de menor massa. Em média, as massas de ramos foram de 9,7 kg/planta para 'Superior Seedless', $8,7 \mathrm{~kg} /$ planta para 'Catalunha', 7,8 kg/planta para 'Crimson Seedless' e 7,3 kg/planta para 'Sultanina'. Os resultados de 'Sultanina' diferem dos dados observados para esta cultivar em Petrolina-PE, quando esta apresentou a maior massa de poda $(9,3 \mathrm{~kg} /$ planta), comparada a outras 12 cultivares (Leão, 2002). Freire et al. (1991) observaram um grande vigor desenvolvido por plantas dessa cultivar, em detrimento do desenvolvimento de gemas florais, quando enxertada no porta-enxerto 'IAC 313 Tropical' nessa mesma região.

A mesma tendência de vigor foi observada para o número de ramos (Tabela 2), sendo a cultivar Superior Seedless (139,1 ramos/planta) a de maior média, com $8 \%$ mais ramos do que 'Catalunha' (128,0 ramos/planta), 10,2\% mais ramos do que 'Crimson Seedless' (124,9 ramos/planta) e 15,5\% mais ramos do que 'Sultanina' (117,5 ramos/planta). Não foram avaliados os números de ramos de 'Sultanina' na segunda e na quarta safras, pois as plantas não apresentaram cachos até o momento da contagem das brotações.

Na média das 5 safras, as maiores fertilidades das gemas, em ordem decrescente, foram observadas para 'Catalunha' $(0,28$ cachos/ramo), 'Crimson Seedless' ( 0,23 cachos/ramo), 'Sultanina' ( $0,21 \mathrm{cachos} / \mathrm{ramo})$ e 'Superior Seedless' (0,08 cachos/ramo) (Tabela 3). A cultivar 'Sultanina' não foi produtiva nas podas realizadas nos meses de janeiro e fevereiro. Leão \& Pereira (2001) recomendam que a poda de 'Sultanina', em Petrolina-PE, deve ser longa, com varas de 10 a 15 gemas, devido às baixas fertilidades nas gemas basais e medianas dos ramos dessa cultivar. Estes autores também observaram grandes variações na fertilidade de gemas ao longo dos ciclos de produção para as cultivares Vênus, Arizul, Beauty Seedless, Marroo Seedless e Canner Seedless.

As maiores médias para número de cachos por planta, nas 5 safras, em ordem decrescente, foram encontradas para 'Catalunha' (37,4 cachos/planta), 'Crimson Seedless' (28,3 cachos/ planta), 'Sultanina' (24,3 cachos/planta) e 'Superior Seedless' (12,5 cachos/planta) (Tabela 4). Na região de Jaboticabal, Leão et al. (2000) observaram que, em plantas da cultivar Superior Seedless sobre 'IAC 572 Jales', foram colhidos 22 cachos por planta; entretanto, nessa região, faz-se somente uma colheita ao ano. Leão (2002) relatou que a produção de 'Sultanina' no vale do São Francisco foi menor do que a observada neste experimento, com apenas 15 cachos por planta em cada safra do ano. Essa cultivar foi uma das menos produtivas dentre 13 
cultivares avaliadas, juntamente com 'Emperatriz', 'Canner Seedless' e 'Loose Perlette'. Camargo et al. (1997) obtiveram 23.217 cachos/ha/safra de 'Catalunha' na região do vale do São Francisco, inferior aos 41.556 cachos/ha/safra para a mesma cultivar neste experimento. Para 'Crimson Seedless', conduzida em manjedoura, em Pirapora-MG, Camargo et al. (2003) efetuaram a colheita de 19,6 cachos por planta, onde se realiza apenas uma safra ao ano, número também abaixo do observado neste experimento.

As médias de massa de cachos por planta foram maiores para 'Catalunha' ( $8,6 \mathrm{~kg} /$ planta), seguidas por 'Crimson Seedless' (6,3 kg/planta), 'Sultanina' (5,7 kg/planta) e 'Superior Seedless' (2,9 kg/planta) (Tabela 5). A produção de 'Superior Seedless' foi maior em Petrolina-PE, com 5,4 quilos por planta, em média (Grangeiro et al., 2002). Para 'Sultanina', na mesma região, a média de 2,4 quilos de uvas por planta observada por Leão (2002) foi inferior aos 5,7 quilos por planta obtidos neste experimento. Camargo et al. (2003) constataram produções de 14,44; 10,19; 12,41 e 0,0 kg/planta/ano para 'Sultanina', 'Crimson Seedless', 'Catalunha' e 'Superior Seedless' conduzidas em manjedoura, em Pirapora-MG. Esses dados, no entanto, são referentes a apenas uma safra, sendo necessárias repetições para verificar se essa produção por planta se repete em outras safras.

As melhores produtividades obtidas ocorreram na primeira safra de cada ano, quando a poda foi realizada no final do período chuvoso, e a colheita, nos meses de junho e julho (Tabela 6). A exceção foi para a cultivar Superior Seedless, que apresentou produtividade inconstante. Na primeira safra, as plantas dessa cultivar ainda não estavam totalmente formadas, e a produtividade foi muito baixa. Também não houve diferença significativa entre as produtividades observadas para essa cultivar na quarta e na quinta safras. A diferença de produtividade entre os primeiros e os segundos semestres foi de 11,5t/ha para 'Catalunha', 10,5t/ha para 'Sultanina', 7,1t/ha para 'Crimson Seedless' e 1,2t/ha para 'Superior Seedless'. Diferentemente, em Petrolina-PE, a melhor produtividade de 'Superior Seedless' foi observada na safra com colheita realizada no segundo semestre do ano (Grangeiro et al., 2002). A melhor média de produtividade, no conjunto de todas as safras, foi observada para a cultivar Catalunha (9,5t/ha), seguida por 'Crimson Seedless' (7,0t/ha), 'Sultanina' (6,3t/ha) e, por último, 'Superior Seedless' (3,2t/ha). Entretanto, quando se considerou somente a média de produtividade dos primeiros semestres, observou-se aumento considerável nesses valores, com 14,1t/ha para 'Catalunha', 10,5t/ ha para 'Sultanina', 9,8t/ha para 'Crimson Seedless' e 3,7t/ha para 'Superior Seedless'. Para a cultivar Superior Seedless, em Petrolina-PE, Grangeiro et al. (2002) obtiveram produtividades de 7,41 e 3,2t/ha no segundo semestre de 1999 e primeiro semestre de 2000 , respectivamente, em plantas no segundo ano de produção. Esses resultados foram superiores às médias de 5 safras obtidas neste experimento, em Jaíba-MG; entretanto, quando consideradas as produtividades das plantas aos 2 anos de idade, foram obtidas 6,7 e 3,7t/ha, para o primeiro e segundo semestres de 2004, respectivamente. Leão et al. (2000) obtiveram produtividade estimada de $6,6 \mathrm{t} / \mathrm{ha}$ para essa cultivar, na região de Jaboticabal-SP; entretanto estes autores não descreveram a idade das plantas. Para plantas conduzidas em manjedoura, em Pirapora-MG, Camargo et al. (2003) obtiveram produtividades de 21,$7 ; 15,3 ; 18,6$ e $0,0 t /$ ha/ano, para 'Sultanina', 'Crimson Seedless', 'Catalunha' e 'Superior Seedless', enxertadas em 'IAC 572 Jales'.

TABELA 1 - Massa de ramos podados das videiras 'Catalunha', 'Sultanina', 'Crimson Seedless' e 'Superior Seedless' em Jaíba - MG, do segundo semestre de 2003 até o primeiro semestre de 2005 .

\begin{tabular}{cccccc}
\hline \multicolumn{5}{c}{ Massa de ramos podados por planta (quilos) } \\
Cultivar & $2^{\circ}$ semestre $\mathbf{0 3}$ & $1^{\circ}$ semestre 04 & $2^{\circ}$ semestre 04 & $1^{\circ}$ semestre 05 & média \\
\hline Catalunha & $10,1 \mathrm{ab}$ & $5,4 \mathrm{a}$ & $11,6 \mathrm{ab}$ & $7,8 \mathrm{a}$ & 8,7 \\
Sultanina & $6,0 \mathrm{~b}$ & $4,9 \mathrm{a}$ & $10,1 \mathrm{bc}$ & $8,3 \mathrm{a}$ & 7,3 \\
Crimson S. & $9,7 \mathrm{ab}$ & $4,4 \mathrm{a}$ & $8,3 \mathrm{c}$ & $8,9 \mathrm{a}$ & 7,8 \\
Superior S. & $12,0 \mathrm{a}$ & $4,8 \mathrm{a}$ & $14,0 \mathrm{a}$ & $8,1 \mathrm{a}$ & 9,7 \\
\hline D.M.S. $\mathbf{( 5 \% )}$ & 4,30 & 1,73 & 2,88 & 3,81 & $\cdots$ \\
F : & $5,203^{* *}$ & $0,953^{\text {ns }}$ & $10,338^{* *}$ & $0,257^{\text {ns }}$ & $\cdots$ \\
\hline CV $(\%)$ & 30,85 & 24,16 & 17,79 & 31,23 & $\cdots$ \\
\hline
\end{tabular}

Médias seguidas de mesma letra não diferem entre si, pelo Teste de Tukey. ** = significativo a $1 \%$ de probabilidade; ns = não-significativo.

TABELA 2 - Número de ramos das videiras 'Catalunha', 'Sultanina', 'Crimson Seedless' e 'Superior Seedless' em Jaíba - MG, do primeiro semestre de 2003 até o primeiro semestre de 2005.

\begin{tabular}{ccccccc}
\hline \multicolumn{7}{c}{ Número de ramos por planta } \\
Cultivar & $1^{\circ}$ semestre 03 & $2^{\circ}$ semestre 03 & $1^{\circ}$ semestre 04 & $2^{\circ}$ semestre 04 & $1^{\circ}$ semestre 05 & média \\
\hline Catalunha & $75,8 \mathrm{ab}$ & $133,3 \mathrm{~b}$ & $158,3 \mathrm{a}$ & $110,1 \mathrm{ab}$ & $162,6 \mathrm{a}$ & 128,0 \\
Sultanina & $71,6 \mathrm{~b}$ & --- & $155,0 \mathrm{a}$ & $-\ldots-$ & $125,9 \mathrm{a}$ & 117,5 \\
Crimson S. & $96,0 \mathrm{a}$ & $135,6 \mathrm{~b}$ & $151,7 \mathrm{a}$ & $108,1 \mathrm{~b}$ & $132,9 \mathrm{a}$ & 124,9 \\
Superior S. & $95,0 \mathrm{a}$ & $175,6 \mathrm{a}$ & $171,9 \mathrm{a}$ & $126,1 \mathrm{a}$ & $127,0 \mathrm{a}$ & 139,1 \\
\hline D.M.S. (5\%) & 22,97 & 20,25 & 26,31 & 16,53 & 41,44 & $\cdots$ \\
F : & $4,570^{* *}$ & $17,991^{* *}$ & $1,722 \mathrm{~ns}$ & $4,648^{*}$ & $2,646 \mathrm{~ns}$ & --- \\
\hline CV (\%) & 19,88 & 10,01 & 11,22 & 10,55 & 20,50 & $\cdots$ \\
\hline
\end{tabular}

Médias seguidas de mesma letra não diferem entre si, pelo Teste de Tukey. $* *$ significativo a $1 \%$ de probabilidade; $*=$ significativo a $5 \%$ de probabilidade; ns = não-significativo.

TABELA 3 - Fertilidade de gemas das videiras 'Catalunha', 'Sultanina', 'Crimson Seedless' e 'Superior Seedless' em Jaíba - MG, do primeiro semestre de 2003 até o primeiro semestre de 2005.

\begin{tabular}{|c|c|c|c|c|c|c|}
\hline \multirow[b]{2}{*}{ Cultivar } & \multicolumn{6}{|c|}{ Fertilidade de gemas ( $\mathrm{n}^{0}$ cachos $/ \mathrm{n}^{\circ}{ }^{\circ}$ amos) } \\
\hline & $1^{0}$ semestre 03 & $2^{\circ}$ semestre 03 & $1^{0}$ semestre 04 & $2^{0}$ semestre 04 & $1^{0}$ semestre 05 & média \\
\hline Catalunha & $0,42 \mathrm{a}$ & 0,17 a & $0,39 \mathrm{ab}$ & $0,09 \mathrm{a}$ & 0,34 a & 0,28 \\
\hline Sultanina & $0,34 \mathrm{a}$ & $0,00 \mathrm{c}$ & 0,45 a & $0,00 \mathrm{~b}$ & $0,25 a b$ & 0,21 \\
\hline Crimson S. & $0,42 \mathrm{a}$ & $0,08 \mathrm{~b}$ & $0,30 \mathrm{bc}$ & 0,11 a & $0,26 \mathrm{a}$ & 0.23 \\
\hline Superior S. & $0,01 \mathrm{~b}$ & $0,03 \mathrm{bc}$ & $0,17 \mathrm{c}$ & $0,10 \mathrm{a}$ & $0,09 \mathrm{~b}$ & 0,08 \\
\hline D.M.S. $(5 \%)$ & 0,15 & 0,051 & 0,14 & 0,044 & 0,16 & $\ldots$ \\
\hline $\mathrm{F}:$ & $23,791^{* *}$ & $31,158^{* *}$ & $11,690^{* *}$ & $20,525^{* *}$ & $6,293 * *$ & $\ldots$ \\
\hline $\mathrm{CV}(\%)$ & 35,22 & 50,63 & 28,54 & 39,76 & 46,91 & ...- \\
\hline
\end{tabular}

Médias seguidas de mesma letra não diferem entre si, pelo Teste de Tukey. $* *=$ significativo a $1 \%$ de probabilidade. 
TABELA 4 - Número de cachos das videiras 'Catalunha', 'Sultanina', 'Crimson Seedless' e 'Superior Seedless' em Jaíba - MG, do primeiro semestre de 2003 até o primeiro semestre de 2005.

\begin{tabular}{ccccccc}
\hline \multicolumn{5}{c}{ Número de cachos por planta } \\
Cultivar & $\mathbf{1}^{\circ}$ semestre 03 & $\mathbf{2}^{\circ}$ semestre 03 & $\mathbf{1}^{\circ}$ semestre 04 & $\mathbf{2}^{\circ}$ semestre 04 & $\mathbf{1}^{\circ}$ semestre 05 & média \\
\hline Catalunha & $33,0 \mathrm{a}$ & $22,9 \mathrm{a}$ & $62,3 \mathrm{a}$ & $9,4 \mathrm{a}$ & $59,3 \mathrm{a}$ & 37,4 \\
Sultanina & $25,3 \mathrm{a}$ & $0,0 \mathrm{c}$ & $65,7 \mathrm{a}$ & $0,0 \mathrm{~b}$ & $30,4 \mathrm{ab}$ & 24,3 \\
Crimson S. & $40,0 \mathrm{a}$ & $10,7 \mathrm{~b}$ & $44,3 \mathrm{~b}$ & $11,7 \mathrm{a}$ & $35,0 \mathrm{ab}$ & 28,3 \\
Superior S. & $1,3 \mathrm{~b}$ & $5,6 \mathrm{bc}$ & $29,6 \mathrm{~b}$ & $13,3 \mathrm{a}$ & $12,7 \mathrm{~b}$ & 12,5 \\
\hline D.M.S. (5\%) & 19,13 & 7,39 & 15,67 & 4,92 & 32,04 & $\cdots$ \\
F : & $11,811^{* *}$ & $26,534^{* *}$ & $17,502^{* *}$ & $22,331^{* *}$ & $5,467 * *$ & $\cdots$ \\
\hline CV (\%) & 52,10 & 51,18 & 21,06 & 38,72 & 63,23 & $\cdots$ \\
\hline
\end{tabular}

Médias seguidas de mesma letra não diferem entre si, pelo Teste de Tukey. $* *=$ significativo a $1 \%$ de probabilidade.

TABELA 5 - Massa total de cachos das videiras 'Catalunha', 'Sultanina', 'Crimson Seedless' e 'Superior Seedless' em Jaíba - MG, do primeiro semestre de 2003 até o primeiro semestre de 2005.

\begin{tabular}{ccccccc}
\hline \multicolumn{7}{c}{ Massa total de cachos por planta (quilos) } \\
Cultivar & $\mathbf{1}^{\circ}$ semestre $\mathbf{0 3}$ & $\mathbf{2}^{\circ}$ semestre $\mathbf{0 3}$ & $\mathbf{1}^{\circ}$ semestre 04 & $2^{\circ}$ semestre 04 & $\mathbf{1}^{\circ}$ semestre 05 & média \\
\hline Catalunha & $11,5 \mathrm{a}$ & $2,9 \mathrm{a}$ & $9,5 \mathrm{ab}$ & $1,8 \mathrm{a}$ & $17,1 \mathrm{a}$ & 8,6 \\
Sultanina & $6,7 \mathrm{a}$ & $0,0 \mathrm{c}$ & $12,5 \mathrm{a}$ & $0,0 \mathrm{~b}$ & $9,2 \mathrm{ab}$ & 5,7 \\
Crimson S. & $7,3 \mathrm{a}$ & $2,3 \mathrm{ab}$ & $8,9 \mathrm{ab}$ & $2,5 \mathrm{a}$ & $10,3 \mathrm{ab}$ & 6,3 \\
Superior S. & $0,2 \mathrm{~b}$ & $1,2 \mathrm{bc}$ & $6,0 \mathrm{~b}$ & $3,3 \mathrm{a}$ & $3,8 \mathrm{~b}$ & 2,9 \\
\hline D.M.S. (5\%) & 6,37 & 1,32 & 3,76 & 1,59 & 9,01 & $\cdots$ \\
F : & $8,222^{* *}$ & $14,562^{* *}$ & $7,654^{* *}$ & $11,883^{* *}$ & $5,602 *$ & $\cdots$ \\
\hline CV (\%) & 67,31 & 55,45 & 27,69 & 56,89 & 60,57 & $\cdots$ \\
\hline
\end{tabular}

Médias seguidas de mesma letra não diferem entre si, pelo Teste de Tukey. ** = significativo a $1 \%$ de probabilidade.

TABELA 6 - Produtividade estimada por hectare, das videiras 'Catalunha', 'Sultanina', 'Crimson Seedless' e 'Superior Seedless' em Jaíba - MG, safras de 2003 a 2005 .

\begin{tabular}{ccccc}
\hline Período & $\begin{array}{c}\text { Catalunha } \\
\text { (tonelada/ha) }\end{array}$ & $\begin{array}{c}\text { Sultanina } \\
\text { (tonelada/ha) }\end{array}$ & $\begin{array}{c}\text { Crimson S. } \\
\text { (tonelada/ha) }\end{array}$ & $\begin{array}{c}\text { Superior S. } \\
\text { (tonelada/ha) }\end{array}$ \\
\hline $\mathbf{1}^{\circ}$ semestre 2003 & $12,8 \mathrm{a}$ & $7,4 \mathrm{~b}$ & $8,1 \mathrm{a}$ & $0,2 \mathrm{c}$ \\
$\mathbf{2}^{\circ}$ semestre 2003 & $3,2 \mathrm{~b}$ & $0,0 \mathrm{c}$ & $2,6 \mathrm{~b}$ & $1,3 \mathrm{c}$ \\
$\mathbf{1}^{\circ}$ semestre 2004 & $10,6 \mathrm{a}$ & $13,9 \mathrm{a}$ & $9,9 \mathrm{a}$ & $6,7 \mathrm{a}$ \\
$\mathbf{2}^{\circ}$ semestre 2004 & $2,0 \mathrm{~b}$ & $0,0 \mathrm{c}$ & $2,8 \mathrm{~b}$ & $3,7 \mathrm{~b}$ \\
$\mathbf{1}^{\circ}$ semestre 2005 & $19,0 \mathrm{a}$ & $10,2 \mathrm{~b}$ & $11,4 \mathrm{a}$ & $4,2 \mathrm{~b}$ \\
\hline Total & 47,6 & 31,6 & 34,8 & 16,1 \\
\hline média ${ }^{1}$ semestre & 14,1 & 10,5 & 9,8 & 3,7 \\
média 2 ${ }^{\circ}$ semestre & 2,6 & 0,0 & 2,7 & 2,5 \\
\hline média por safra & 9,5 & 6,3 & 7,0 & 3,2 \\
média anual & 19,0 & 12,6 & 13,9 & 6,4 \\
\hline
\end{tabular}

Médias seguidas de mesma letra na coluna não diferem entre si, pelo Teste de Scott Knott, a 5\% de probabilidade.

\section{CONCLUSÕES}

O ciclo entre poda e colheita oscilou entre 97 e 125 dias para as cultivares estudadas.

1-As maiores produtividades foram obtidas no ciclo de produção do primeiro semestre para todas as cultivares estudadas.

2-A produtividade média oscilou entre 19,0 e $6,4 \mathrm{t} / \mathrm{ha}$, destacando-se 'Catalunha' e 'Superior Seedless' como as de maior e menor produtividade, respectivamente.

\section{REFERÊNCIAS}

AGRIANUAL 2006: anuário da agricultura brasileira. Uva. São Paulo: FNP Consultoria \& Comércio, 2005. p. 493-504.

BRASIL. Ministério da Agricultura. Estatísticas. Disponível em: $<$ http://www.agricultura.gov.br>. Acesso em: 17 fev. 2006.

CAMARGO, U.A.; MASHIMA, C.H.; CZERMAINSKI, A.B.C. Avaliação de cultivares apirênicas no Vale do São Francisco. Bento Gonçalves: EMBRAPA CNPUV, 1997. 8p. (Comunicado Técnico, 26).

CAMARGO, U.A.; NACHTIGAL, J.C.; PINTO, D.C.R. Comportamento produtivo da videira, cultivares Thompson, Crimson, Catalunha e Superior, no sistema de condução em Y. In: CONGRESSO BRASILEIRO DE VITICULTURAE ENOLOGIA, 10., 2003, Bento Gonçalves-RS. Anais... Bento Gonçalves, EMBRAPA, 2003.p.207.

CODEVASF - COMPANHIADEDESENVOLVIMENTODOVALE DO SÃO FRANCISCO. Informações edafoclimáticas. Disponível em $<$ http://www.codevasf.com.br>. Acesso em: 24 abr 2004.

FEITOSA, C.A.M. Efeitos do CPPU e GA no cultivo de uva Itália na região do Submédio São Francisco, Nordeste do Brasil. Revista Brasileira de Fruticultura, Jaboticabal, v.24, n.2, p. 348353, 2002.

FREIRE, L.C.L.; ALBUQUERQUE, J.A.S. de; ALBUQUERQUE, T.C.S. de. Comportamento da cultivar 'Thompson Seedless' sobre diferentes porta-enxertos na região do Submédio São Francisco. Revista Brasileira de Fruticultura, Jaboticabal, v.13, n.2, p. 129133, 1991.

GRANGEIRO, L.C.; LEÃO, P.C. de S.; SOARES, J.M. Caracterização fenológica e produtiva da variedade de uva Superior Seedless cultivada no Vale do São Francisco. Revista Brasileira de Fruticultura, Jaboticabal, v.24, n.2, p. 552-554, 2002.

LAGOS, S.A.E. Mercado Internacional de uva de mesa. In: CONGRESSO LATINO-AMERICANO DE VITICULTURA E 
ENOLOGIA, 10., 2005, Bento Gonçalves. Anais... Bento Gonçalves: Embrapa Uva e Vinho, 2005. p.93-103.

LEÃO, P.C. de S. Comportamento de cultivares de uva sem sementes no Submédio São Francisco. Revista Brasileira de Fruticultura, Jaboticabal, v.24, n.3, p. 734-737, 2002.

LEÃO, P.C. de S.; NACHTIGAL, J.C.; PEREIRA, F.M.; KOBA, V.Y. Comportamento fenológico e produtivo das variedades de uva "Ribol" e "Superior Seedless" na região de Jaboticabal-SP. Revista Brasileira de Fruticultura, Jaboticabal, v.22, n.2, p. 300302,2000
LEÃO, P.C. de S.; PEREIRA, F.M. Estudo da brotação e da fertilidade de gemas de cultivares de uvas sem sementes nas condições tropicais do Vale do Submédio São Francisco. Revista Brasileira de Fruticultura, Jaboticabal, v.23, n.1, p. 30-34, 2001.

PROTAS, J.F. da S. Introdução. In: NACHTIGAL, J.C. et al. (Ed.). Sistemas de produção 01: uvas sem sementes cultivares BRS Clara, BRS Linda e BRS Morena. Bento Gonçalves: EMBRAPA, 2004. p.9-10. 